\title{
PROMOTIONAL PACKAGING FROM CARTON OF INVASIVE ALIENT PLANT
}

\author{
Kaja Klančar, Urška Vrabič Brodnjak \\ University of Ljubljana, Faculty of Natural Sciences and Engineering, Department of Textiles, \\ Graphic Arts and Design, Ljubljana, Slovenia
}

\begin{abstract}
In this research, the design of innovative promotional packaging made of carton, which was made from the invasive, non-native acacia is presented. The entire planning process was based on the principle of ecological design. One of the main objectives was to create an innovative and versatile ecological product, a calendar that does not require any adhesive in its composition. The basic, mechanical, surface and structural properties of the ecological carton with a high grammage made of acacia compared them with the most commonly used one-side coated white cardboard made of wood fibres has been analysed. The result of this work is the environmentally friendly multi-purpose promotional packaging, the calendar, which could also be used as a storage place for pens and other office supplies.
\end{abstract}

Key words: bio based polymer, eco design, analysis, material.

\section{INTRODUCTION}

The main function of packaging is to store and protect the product during transport, storage, use and external influences. Together with the product, it must form a whole, and its construction must be simple, original and functional. It can be made of various materials and also economic efficiency should be taken into consideration (Shah et al, 2013; Tencati et al, 2016, Schoonbrood et al, 2016). The importance of packaging has increased rapidly in recent years, as thousands of new products are launched each year. Advanced technological development and the use of new materials and design processes have brought the importance of packaging to a higher level. The original purpose, to protect and inform the product, was to take the form of advertising and appeal to the purchase decision. Packaging has thus become an integral part of the product, the basis of advertising and an important marketing tool offering a wide range of business opportunities (Kumar et al, 2017; Hahladakis and lacovidou, 2018; Hawkins, 2020; Shekhar and Raveendran, 2016).

Promotional packaging is characterized by its innovative, unique shape, design or even interactivity, which makes it stand out from the crowd. This includes products that leave a lasting impression, gift packaging that is a gift in itself and sales packaging that educates, motivates or pampers.

Nowadays, the market offers us a wide range of materials that can be used to produce promotional and gift packaging. It can be chosen between paper, cardboard, paperboard, carton, glass, metal, wood, plastic, etc. The choice of material is usually based on the properties and usability of the product, although several materials can also be combined (Tomar and Gaur, 2017; Hawkins, 2020).

The aim of the research was the production of an environmentally friendly promotional product, which does not require an adhesive in its composition, but includes guidelines for sustainable development after use. A calendar for the promotional product, which we wanted to transform into an unusual image, in order to achieve more functionality and user-friendliness has been made.

The primary material for the production of the final product-the promotional packaging was carton made from fibres of invasive alien plant acacia (Nentwig et al, 2017). One-sided coated carton made of wood fibres was used for comparison, as it is better known and most commonly used in the production of packaging.

On the basis of measurements of ecological acacia carton and one-side coated wood fibre board, the analysis of basic (basis weight, thickness, density), mechanical (resistance to cracking, bending stiffness), surface (roughness, porosity, surface absorption), water and structural properties (capillary absorption) have been carried out.

It has been found that organic acacia carton is suitable for lighter packaging forms that do not require greater strength. Despite its softer structure, lower tensile strength, its great advantage is its hydrophobicity, since without coating it has very similar (non-)absorbency results to wood fibre boards coated on one side. In addition to functionality, the appearance of packaging is also important. Its ecological elements make it stand out from the mass of promotional gifts or packaging. It is designed for easy handling, contains a minimalist and transparent design, and moreover the product is designed for 
multi-purpose use. By designing such products, we would certainly contribute to reducing the amount of packaging waste, thus reducing the negative impact on the environment.

\section{MATERIALS AND METHODS}

\subsection{Materials}

To manufacture the final product two different cartons were used, as described below.

Sample 1 (S1)

The first sample used for the final product was a high-grade carton from an invasive plant species, the acacia. It was produced within the European APPLAUSE project, namely at the Institute of Pulp and Paper in Ljubljana.

Sample 2 (S2)

The second sample used was a $300 \mathrm{~g} / \mathrm{m}^{2}$ white wood folding carton, coated on one side: with a glossy coated side $A$ and a matt finish on $B$ side.

\subsection{Methods}

At the research analysis of the materials (sample 1 and 2) such as grammage, thickness, density, bursting resistance, roughness, porosity and absorptiveness were performed.

\subsubsection{Basic properties (grammage, thickness and density)}

Grammage of samples was determined in accordance with the ISO 536 standard. The thickness of samples was with a precision digital micrometre, to the nearest $0.0001 \mu \mathrm{m}$ at 10 random locations on each paper measured. Both analysis done at whole package and separately for each layer, where necessary.

\subsubsection{Bursting strength}

The method was performed according to the SIST EN ISO 2758: 2014 standard. It determines how much pressure is needed to break through paper or cardboard. For each sample, 10 specimens were analyzed.

\subsubsection{Roughness and porosity}

The roughness was determined by Bendtsen method which determines the amount of air ( $\mathrm{ml} / \mathrm{min}$ ) that passes between the measuring ring of the measuring head of the apparatus and the surface of the test piece. Higher airflow along the surface of the test specimen means greater surface roughness. The method was performed according to the ISO 8791-2: 2013 standard.

The porosity analyzed by Bendtsen method determines the amount of air $(\mathrm{ml} / \mathrm{min})$ that passes through the test piece. In general, it is about permeability or. absorbency of the printing material, which affects the speed and quality of absorption of the printing ink. The method was performed according to the ISO 5636-3: 2013 standard.

\subsubsection{Absorptiveness (Cobb value)}

Absorptiveness (the Cobb60 value, $\mathrm{g} / \mathrm{m}^{2}$ ) was determined as described in the standard method ISO 535. For each sample packaging, 10 sample tests were made.

After that the development and design of promotional packaging has been proceeded, using program Engview Package and Display Designer and cutter Esko Kongsberg.

\section{RESULTS AND DISCUSSION}

\subsection{Material analysis}

From Table 1, which presents the results of the basic properties of the samples, it can be seen that the sample of S2 is slightly thicker than the sample S1, while it also has a higher basis weight and density. The weight of the sample S2 is $298.2 \mathrm{~g} / \mathrm{m}^{2}$, density of $743 \mathrm{~kg} / \mathrm{m}^{3}$, a thickness measured $0.402 \mathrm{~mm}$, while the 
basis weight of the sample S1 is $210.9 \mathrm{~g} / \mathrm{m}^{2}$, density of $526 \mathrm{~kg} / \mathrm{m}^{3}$, a thickness of $0.401 \mathrm{~mm}$. In addition to the thickness, which strongly influences the density of the material, the amount of trapped air in the structure of the material, finishing, the binding capacity of the fibers and the substances that fill the gaps in the material also play an important role.

Table 1: Average value, standard deviation and coefficient of variation of the basic properties of samples S1 and S2.

\begin{tabular}{|c|c|c|c|c|}
\hline \multicolumn{2}{|c|}{} & $\begin{array}{c}\text { Grammage } \\
{\left[\mathrm{g} / \mathrm{m}^{2}\right]}\end{array}$ & $\begin{array}{c}\text { Thickness } \\
{[\mathrm{mm}]}\end{array}$ & $\begin{array}{c}\text { Density } \\
{\left[\mathrm{kg} / \mathrm{m}^{3}\right]}\end{array}$ \\
\hline \multirow{3}{*}{ S1 } & $\bar{x}$ & 210.9 & 0.401 & 526 \\
\cline { 2 - 5 } & $\mathrm{S}_{\mathrm{x}}$ & 3.393 & 0.009 & 9.730 \\
\cline { 2 - 6 } & $\mathrm{CV}[\%]$ & 1.61 & 2.26 & 1.85 \\
\hline \multirow{3}{*}{ S2 } & $\overline{\mathrm{x}}$ & 298.2 & 0.402 & 743 \\
\cline { 2 - 6 } & $\mathrm{S}_{\mathrm{x}}$ & 3.208 & 0.004 & 9.943 \\
\cline { 2 - 6 } & $\mathrm{CV}[\%]$ & 1.08 & 1.01 & 1.34 \\
\hline
\end{tabular}

Higher values in the S2 sample were expected, as higher grammage and density required more puncture pressure. In addition, the shorter fibres present in the composition of sample S1 reduce the crack resistance, so the values here in this sample are lower.

Table 2: Average value, standard deviation and coefficient of variation of bursting resistance of samples S1 and S2 on $A$ and $B$ side.

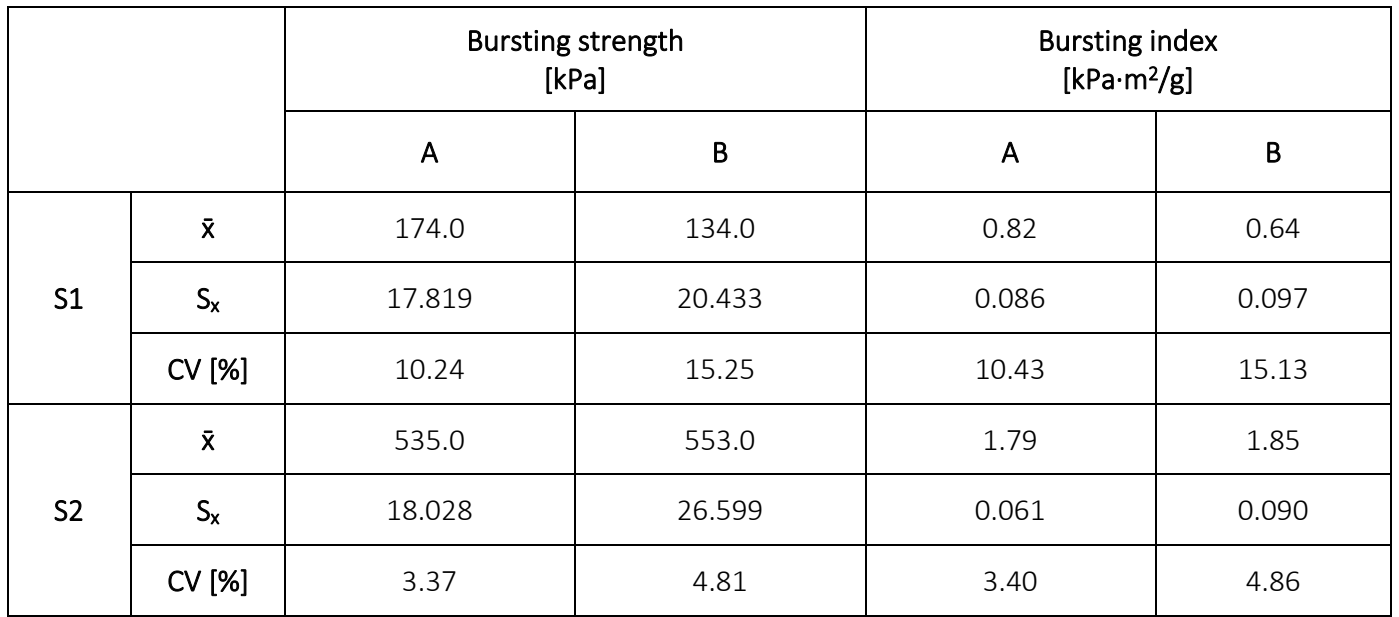

The roughness indicated in Table 3 for sample $\mathrm{S} 2$ is $56.5 \mathrm{ml} / \mathrm{min}$ on side $\mathrm{A}$ and $123.0 \mathrm{ml} / \mathrm{min}$ on side $\mathrm{B}$. The A-side has a glossy coating so that the roughness is lower than on the B-side, which is more matte. The sample $\mathrm{S} 1$ is much rougher and measures $2124.0 \mathrm{ml} / \mathrm{min}$ on side A and $2090.0 \mathrm{ml} / \mathrm{min}$ on side B. A greater roughness was expected in sample S1, since the difference between the samples already scans the tactile properties. Furthermore, sample S1 is made of organic material (acacia plant parts) and does not contain any subsequent processing such as smoothing, coating, etc. 
Table 3: Mean value, standard deviation and Bendtsen roughness and porosity of samples S1 and S2.

\begin{tabular}{|c|c|c|c|c|c|}
\hline & & \multicolumn{2}{|c|}{$\begin{array}{l}\text { Roughness } \\
{[\mathrm{ml} / \mathrm{min}]}\end{array}$} & \multicolumn{2}{|c|}{$\begin{array}{l}\text { Porosity } \\
\text { [ml/min] }\end{array}$} \\
\hline & & $A$ & B & A & B \\
\hline \multirow{3}{*}{ S1 } & $\bar{x}$ & 2124.0 & 2090.0 & 1220.0 & 1195.0 \\
\hline & $S_{x}$ & 122.9 & 126.5 & 42.2 & 43.8 \\
\hline & CV [\%] & 5.8 & 6.1 & 3.5 & 3.7 \\
\hline \multirow{3}{*}{ S2 } & $\bar{x}$ & 56.5 & 123.0 & 0 & 0 \\
\hline & $S_{x}$ & 13.8 & 24.1 & 0 & 0 \\
\hline & $\mathrm{CV}$ [\%] & 24.3 & 19.6 & 0 & 0 \\
\hline
\end{tabular}

Table 4, which shows the water absorptiveness, shows that in the sample S1 measures $88.0 \mathrm{~g} / \mathrm{m}^{2}$ on side $A$ and $82.0 \mathrm{~g} / \mathrm{m}^{2}$ on side $B$, while in the sample $S 2$ measures $78.0 \mathrm{~g} / \mathrm{m}^{2}$ on side $A$ and $84.0 \mathrm{~g} / \mathrm{m}^{2}$ on side $B$. The difference between the sides is small for both samples, namely $6 \mathrm{~g} / \mathrm{m}^{2}$. The absorptiveness is higher on side A in sample $\mathrm{S} 1$ and on side B in sample S2, which is not glossy coated.

Based on the measurement results we can say that both samples have a poor absorption capacity. Both samples are well glued, as the amount of water absorbed in the cardboard paper is very low. Acacia fibres are less absorbent, which is also confirmed by the surface absorption results of sample S1.

Table 4: Mean value, standard deviation and coefficient of variation of water absorption by the Cobb methodabsorptiveness on samples $\mathrm{S} 1$ and $\mathrm{S} 2$.

\begin{tabular}{|c|c|c|c|c|c|c|c|}
\hline & & \multicolumn{2}{|c|}{ A } & \multicolumn{2}{|c|}{ B } & \multicolumn{2}{|c|}{$\begin{array}{l}\text { Absorptiveness } \\
C_{60}\left[\mathrm{~g} / \mathrm{m}^{2}\right]\end{array}$} \\
\hline & & $\mathrm{m}_{1}[\mathrm{~g}]$ & $\mathrm{m}_{2}[\mathrm{~g}]$ & $\mathrm{m}_{1}[\mathrm{~g}]$ & $\mathrm{m}_{2}[\mathrm{~g}]$ & A & B \\
\hline \multirow{3}{*}{ S1 } & $\bar{x}$ & 4.6 & 5.5 & 4.6 & 5.5 & 88.0 & 82.0 \\
\hline & $S_{x}$ & 0.114 & 0.084 & 0.055 & 0.089 & 8.367 & 4.472 \\
\hline & CV [\%] & 2.46 & 1.52 & 1.18 & 1.64 & 9.51 & 5.45 \\
\hline \multirow{3}{*}{ S2 } & $\bar{x}$ & 6.5 & 7.3 & 6.5 & 7.4 & 78.0 & 84.0 \\
\hline & $S_{x}$ & 0.045 & 0.055 & 0.084 & 0.055 & 8.367 & 5.477 \\
\hline & CV [\%] & 0.69 & 0.75 & 1.28 & 0.74 & 10.73 & 6.52 \\
\hline
\end{tabular}

\subsection{Design and the production of final packaging}

In spite of many solutions with the lid and flaps, the final design of the packaging, which is shown in Figure 1, was finally successful. The originally designed construction had 12 flat plots and a perforated lid. The inner flaps were redesigned and arranged alternately on the lid. In order to facilitate handling and to give an innovative image, we have added a perforated cut-out to the lid, which is intended for inserting pens. 


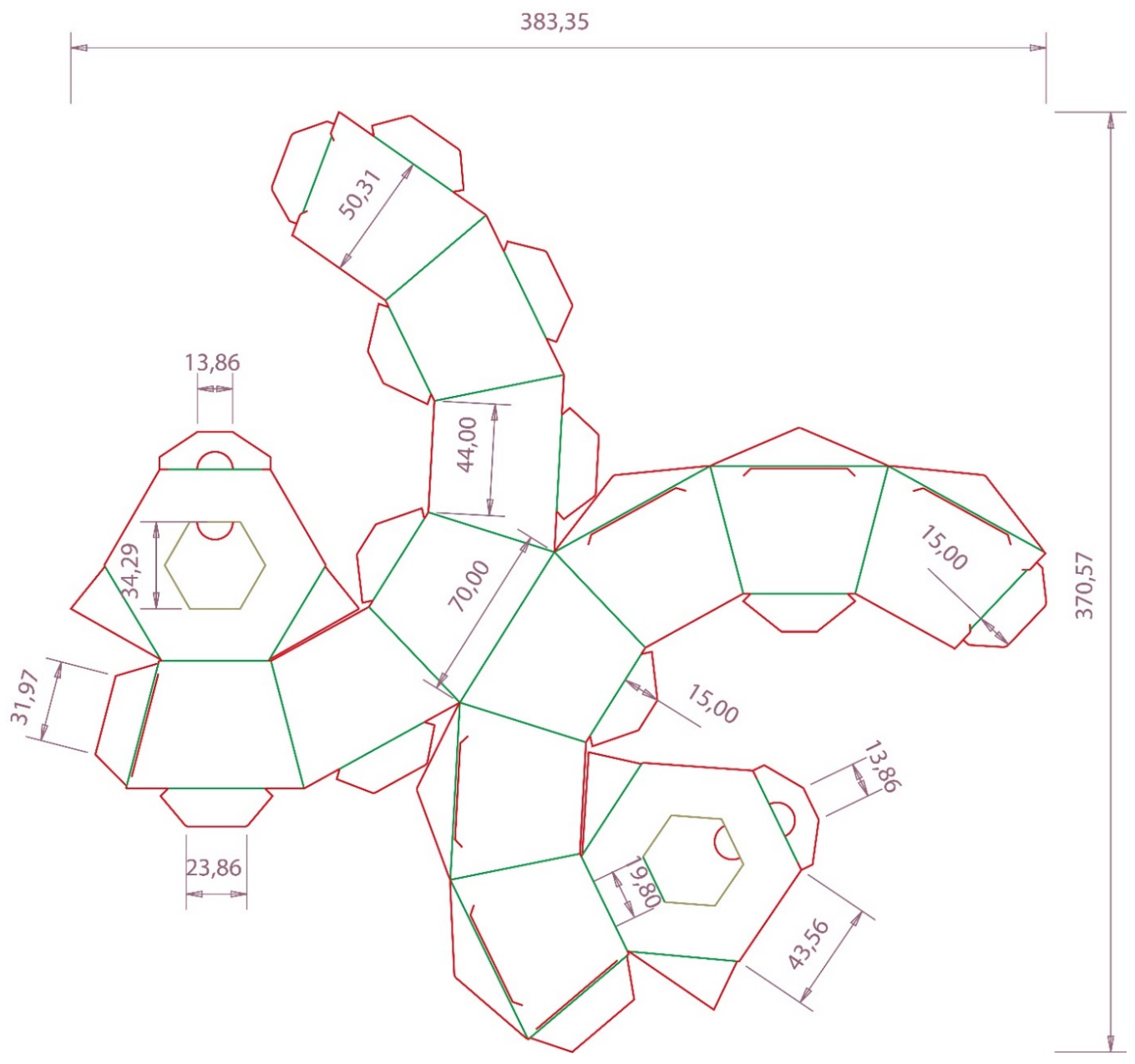

Figure 1: Construction of the final packaging (dimensions are in millimeters)

The drawn construction from the EngView Package \& Display Designer program to the Adobe Illustrator CC 2018 program has been exported. Firstly a calendar, for each month separately has been designed (Figure 2). For the numerical display the linear font Quicksand and displayed names of the months in a Cookie-Regular font that resembles handwriting has been used. The months were arranged over 12 flat plots. Each month was designed on a side surface that had the shape of an isosceles trapezium. The design details also included the illustration of detailed acacia leafs.
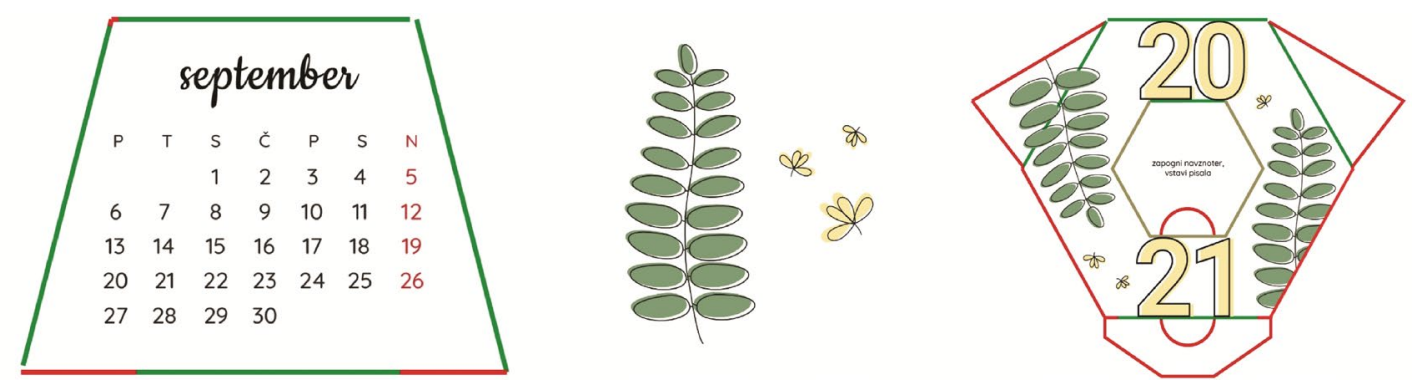

Figure 2: Design details of the packaging

The printed and cut sheet was used to produce the final product as shown in Figure 3. It was folded according to the creasing lines and assembled into the final packaging without adhesive. 

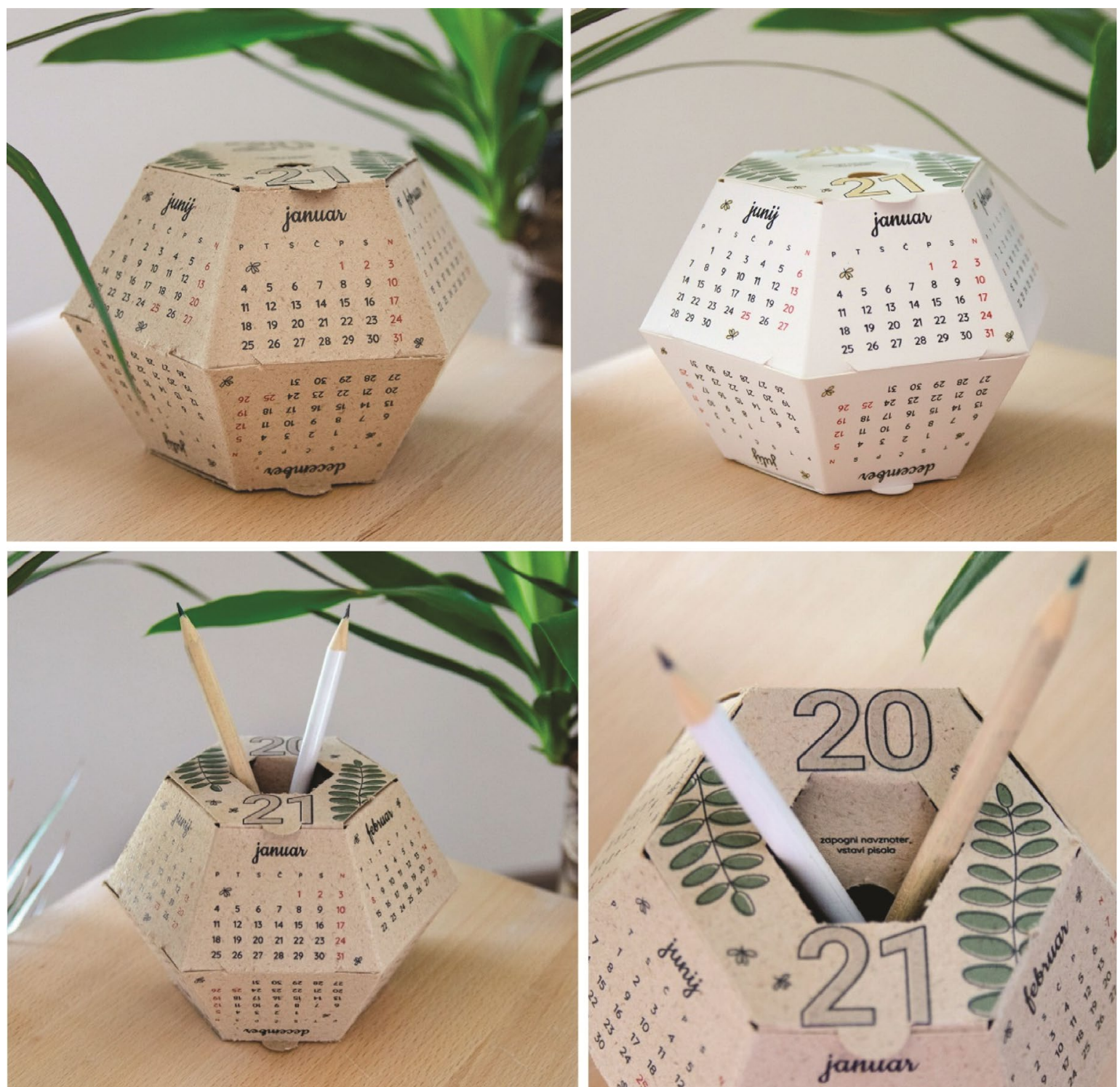

Figure 3: Final printed packaging on both carton samples

\section{CONCLUSIONS}

The main objective was to use the carton of an invasive alien plant - acacia - and more functional form of the calendar. The used high grade ecological carton from acacia was also tested and its basic, mechanical, surface and structural properties were compared with the most commonly used one-side coated carton from wood fibers. It was found that ecological acacia carton is suitable for lighter packaging forms that do not require higher strength. Despite its softer structure or lower strength, its great advantage is its hydrophobicity, since without coating it has very similar (non-)absorption results to single-sided coated wood fiber boards.

In addition to functionality, the appearance of packaging is also important. Its unusual shape and ecological elements make it stand out from the mass of promotional gifts or packaging. It is designed for easy handling, contains a minimalist and transparent design, and moreover the product has a sustainable knowledge as it is designed for multi-purpose use. By designing such products, we would certainly contribute to reducing the amount of packaging waste, thus reducing the negative impact on the environment. 


\section{ACKNOWLEDGMENTS}

The research was supported by the European project Applause (Alien Plant Species from harmful to useful with citizens' led activities) and University of Ljubljana, Faculty of Natural Sciences and Engineering, Department of Textiles, Graphic Arts and Design.

\section{REFERENCES}

[1] Hahladakis, J. N., lacovidou, E.: "Closing the loop on plastic packaging materials: What is quality and how does it affect their circularity?", Science of the Total Environment 630, 1394-1400, 2018. doi: 10.1016/j.scitotenv.2018.02.330

[2] Hawkins, G.: "Detaching from plastic packaging: reconfiguring material responsibilities", Consumption Markets \& Culture, 1-14, 2020. doi: 10.1080/10253866.2020.1803069

[3] Kumar, M., Agarwal, A., Singh, P.: "Green packaging and marketing in promoting agribusiness", Management 3 (1), 2017.

[4] Nentwig, W., Bacher, S., Kumschick, S., Pyšek, P., Vilà, M.: "More than "100 worst" alien species in Europe", Biological Invasions 20 (6), 1611-1621, 2018. doi: 10.1007/s10530-018-1671-x

[5] Schoonbrood, J. M. J.: "Shaping designs: Effects of the graphic design of packaging sales promotion shapes and products' packaging shapes on customers' expectations, pre-purchase attitude and purchase intention", MSc thesis, University of Twente, 2016.

[6] Shah, S., Ahmed, A., Ahmad, N.: "Role of packaging in consumer buying behavior", International Review of Basic and Applied Sciences 1 (2), 35-41, 2013.

[7] Shekhar, S. K., Raveendran, P. T.: "Product Packaging and Competitive Advantage", Asian Journal of Management 7 (1), 1-4, 2016

[8] Tencati, A., Pogutz, S., Moda, B., Brambilla, M., Cacia, C.: "Prevention policies addressing packaging and packaging waste: Some emerging trends", Waste management 56, 35-45, 2016. doi: 10.1016/j.wasman.2016.06.025

[9] Tomar, R. S., Gaur, M. S.: "Packaging-a turnaround way to advertise", Asia Pacific Journal of Research in Business Management 8 (4), 2017.

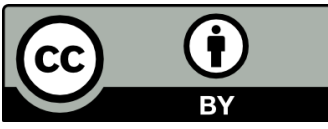

(C) 2020 Authors. Published by the University of Novi Sad, Faculty of Technical Sciences, Department of Graphic Engineering and Design. This article is an open access article distributed under the terms and conditions of the Creative Commons Attribution license 3.0 Serbia (http://creativecommons.org/licenses/by/3.0/rs/). 